\title{
Service limit state resistance factors for drilled shafts
}

\author{
A. MISRA* and L. A. ROBERTS $\dagger$
}

\begin{abstract}
The analysis of bored piles, or drilled shafts, at the service limit state is important when foundation settlements are critical to the operation of a structure. The $t-z$ method is a widely used soil-structure interaction model for the analysis of drilled shaft settlement. In current practice, nominal values of soil stiffness and strength parameters are used to determine settlement based upon the $t-z$ method. However, the nominal values can vary from one designer to another, making the results somewhat inconsistent. By considering reliability-based design principles, probabilistic relationships can be incorporated into the settlement analysis of the drilled shaft, and thus design uncertainty can be quantified. Following this approach, load and resistance factor design (LRFD) procedures may be utilised and resistance factors established for use in design. Using a $t-z$ model and the Monte Carlo simulation process, probability distributions are determined for drilled shaft capacity at the service limit state. Resistance factors are calculated based upon these relationships. The drilled shaft geometry and the shaft/soil interface parameters are varied so that their effects on the resistance factors may be understood.
\end{abstract}

KEYWORDS: limit state design/analysis; numerical modelling; piles; settlement; soil/structure interaction
L'analyse de pieux forés, ou d'arbres percés, à l'état limite de service est importante lorsque le tassement des fondations joue un rôle critique dans l'utilisation d'une structure. La méthode $t-z$ est un modèle très répandu d'interaction sol - structure pour l'analyse du tassement des arbres percés. Dans les applications actuelles, on utilise des valeurs nominales de rigidité du sol et des paramètres de résistance afin de déterminer le tassement sur la base de la méthode $t-z$. Toutefois, les valeurs nominales peuvent varier d'un concepteur à un autre, en produisant ainsi des résultats quelque peu irréguliers. En examinant des principes conceptuels basés sur la fiabilité, des rapports probabilistes peuvent être incorporés dans l'analyse du tassement de l'arbre foré, et on est alors en mesure de quantifier l'incertitude conceptuelle. En suivant ce principe, il est possible d'utiliser des procédures d'étude du facteur de charge et de résistance, et d'établir des facteurs de résistance, qui seront utilisés dans la conception. On procède à la détermination de distributions de la probabilité en appliquant le modèle $t-z$ et la technique de simulation Monte-Carlo, pour la capacité des arbres percés à l'état de service limite. Des facteurs de résistance sont calculés sur la base de ces rapports, et on varie la géométrie des arbres percés et les paramètres d'interface arbre/sol afin de comprendre leurs effets sur les facteurs de résistance.

\section{INTRODUCTION}

The geotechnical design of drilled shafts, also known as bored piles, has traditionally followed the allowable stress design (ASD) methodology at the axial ultimate limit state, assuming full resistance of the soil along the length of the shaft and at the tip. In the design, uncertainty can result from numerous sources: inherent variability, measurement errors, transformation uncertainties (Phoon \& Kulhawy, 1999), and construction techniques. Inherent variability is due to the spatial uncertainty of soil and rocks that results from deposition, consolidation, and so on, while measurement errors and transformation uncertainties result from the tests and correlations used to quantify soil and rock properties. The ASD method accounts for these uncertainties with the use of a factor of safety. However, because the magnitude of the uncertainties is never quantified, the traditional ASD method may result in an inefficient design, creating the need for excess materials or construction time. The introduction of reliability-based design principles in the field of geotechnical engineering, such as the load and resistance factor design (LRFD) approach, has resulted in design methods with the following advantages: the design is easier and more efficient since the load combinations do not need to be redefined; and uncertainty is quantified and rationally incor-

Manuscript received 19 July 2005, revised manuscript accepted 11 August 2008. Published online ahead of print 14 October 2008.

Discussion on this paper closes on 1 July 2009, for further details see p. ii.

* Civil, Environmental and Architectural Engineering Department, University of Kansas, Lawrence, USA.

$\uparrow$ South Dakota School of Mines and Technology, Rapid City, USA. porated into the design process (FHWA, 1999). A reliabilitybased design approach will often produce a design that is more efficient than the traditional factor of safety approach, and will aim to generate a consistent level of safety from one design to another.

The use of single drilled shafts to support individual columns in bridges and buildings is widely practised. The displacement or settlement of a single drilled shaft is important when the foundation movements are critical to the operation of a structure. If the displacement of the system exceeds an allowable value, the system may still be structurally adequate, but it may be unusable or cause user discomfort. The challenge in design is often determining the foundation resistance or load capacity at an allowable displacement. This design criterion is an important aspect of the serviceability limit state in Eurocode 7 (CEN, 2004) or the service limit state design of foundations in AASHTO (2004). While the term 'serviceability limit state' is always used in Eurocode 7, in the United States the term 'service limit state' is often used for foundation design. In this paper, the terms 'serviceability' and 'service limit state' have been used interchangeably. The focus of this work is to develop a reliability-based approach for estimating resistance factors that can be used for the service limit state foundation design.

Very often, a single allowable displacement value that encompasses all types of structure or all design situations is nearly impossible to define. The magnitude of allowable displacements for various structures has been discussed in the literature (Skempton \& MacDonald, 1956; Burland \& Wroth, 1974; Barker et al., 1991; Zhang \& Ng, 2005). However, the tolerable settlements of single deep founda- 
tions are not well defined. At times, the ultimate capacity of foundations is defined at the displacement equal to $5 \%$ of the foundation diameter, if the foundation has not plunged prior to this displacement (DFI, 1990; FHWA, 1999). For bridge structures, angular distortion is often the controlling factor, and is a function not only of vertical displacement of the foundation system, but also of the bridge span lengths (see Barker et al., 1991, which provides a table of allowable displacements for bridges expressed in terms of settlement magnitude and tolerable movements for single-span and multiple-span bridges). Settlement criteria are seldom given in terms of probability distributions or specified in terms equivalent to load factors. Moreover, the drilled shaft may fail owing to plunging under a given factored load. In this case, the settlement would not be definable, and the estimated settlement probability distribution would have a discontinuity. Therefore serviceability limit state design of foundations cannot be performed in a manner analogous to that for strength, with the probability distribution for estimated displacement of the foundation being compared with the probability distribution for tolerable movement of the structure. It is therefore useful to determine the load capacity histogram at which the displacement of the foundation is equal to an allowable displacement (Misra \& Roberts, 2005, 2006).

Using a $t-z$ model of soil-drilled shaft interaction and the Monte Carlo simulation process, probability distributions are determined for drilled shaft capacity at the service limit state. These relationships are analysed to develop resistance factors that may be used for axial service limit state design. In the authors' calculations, the shaft/soil interface is considered to be homogeneous with depth and is modelled assuming hyperbolic load-displacement behaviour. A finite difference technique is utilised to solve the governing differential equations that describe the soil-structure interaction. The shaft/soil interface stiffness and strength parameters are treated as random variables, and their variability is modelled by a log-normal distribution function. The parameters are considered independently, because no significant correlation between these parameters is observed to exist, based upon the correlation coefficient for back-calculated values of the parameters (see also Duncan \& Chang, 1970; Duncan et al., 1980). The Monte Carlo simulation process is utilised to obtain a large set of load-displacement curves, which are analysed to develop probability distributions of load capacity at given displacements. These probability distributions are used to obtain a service limit state 'failure' probability or reliability index and, subsequently, resistance factors for use in design. The results show that these resistance factors are dependent upon the magnitude of the allowable shaft displacement, the coefficient of variation (COV) of the shaft/ soil interface parameters and the drilled shaft length, but have a smaller dependence on the drilled shaft diameter or tip resistance.

\section{DRILLED SHAFT/SOIL INTERACTION MODEL}

The shaft/soil interaction along the length of the soil/ concrete interface of the drilled shaft is represented by a spring-slider system in the $t-z$ method. This model simplifies the shaft/soil interaction zone, and the radial thickness of the soil participating in the interaction does not need to be quantified. Similar assumptions are commonly made for analytical and numerical models for the load-displacement behaviour of piles and drilled shafts as well as pile groups (cf. Randolph \& Wroth, 1978; Kraft et al., 1981; Scott, 1981; Reese \& O’Neill, 1987; FHWA, 1999; Castelli \& Maugeri, 2002; Misra \& Chen, 2004).

Figure 1 shows the force-displacement behaviour for a non-linear spring-slider system, as depicted by the curve of shear force per unit length, $q$, against vertical displacement, $u$. In Fig. $1, K_{\mathrm{i}}$ is the initial tangent shear modulus of shaft/ soil interface subgrade reaction, and $q_{0}$ is the ultimate (asymptotic) strength of the shaft/soil interface, given by the product of the shaft perimeter and the ultimate shear strength of the shaft/soil interface in drained or undrained conditions, denoted by $\tau_{\mathrm{u}}$. In general, the shaft/soil interface parameters are related to the construction techniques and the properties of the soil strata. These interface parameters typically follow the stratification of the natural soil; however, for simplicity, a homogeneous interface is assumed for the calculations in this paper. The horizontal and vertical fluctuations of the interface parameters are considered through a 'lumped' magnitude of uncertainty caused by the various sources mentioned in the introduction. Fenton \& Griffiths (2007) investigated the effect of spatial variability on the serviceability limit state of a deep foundation element using random field finite element analyses. The results of their analyses show that the serviceability limit state failure probability for a deep foundation is maximised when the parameters along the soil/structure interface are assumed as random variables with no spatial correlation. Their finding also suggests that the vertical and horizontal fluctuations need not be considered separately, and conservative results are obtained if the fluctuations are lumped together. This is especially true for deep foundations that derive their capacity from side resistance as the vertical fluctuations tend to average out, as borne out from the current authors' preliminary calculations briefly described later.

The non-linear force-displacement behaviour has been successfully described using a hyperbolic model given by (see Kondner, 1963; Duncan \& Chang, 1970; Duncan et al., 1980):

$$
q=\frac{u}{\left(1 / K_{\mathrm{i}}\right)+\left(u R_{\mathrm{f}} / q_{0}\right)}
$$

where the factor $R_{\mathrm{f}}$, described as the failure ratio, relates the ultimate (asymptotic) strength $q_{0}$ of the load-displacement curve to the observed failure strength $q_{\mathrm{f}}$ according to (Duncan \& Chang, 1970)

$$
R_{\mathrm{f}}=\frac{q_{\mathrm{f}}}{q_{0}}
$$

The factor $R_{\mathrm{f}}$ always has a value less than or equal to unity.

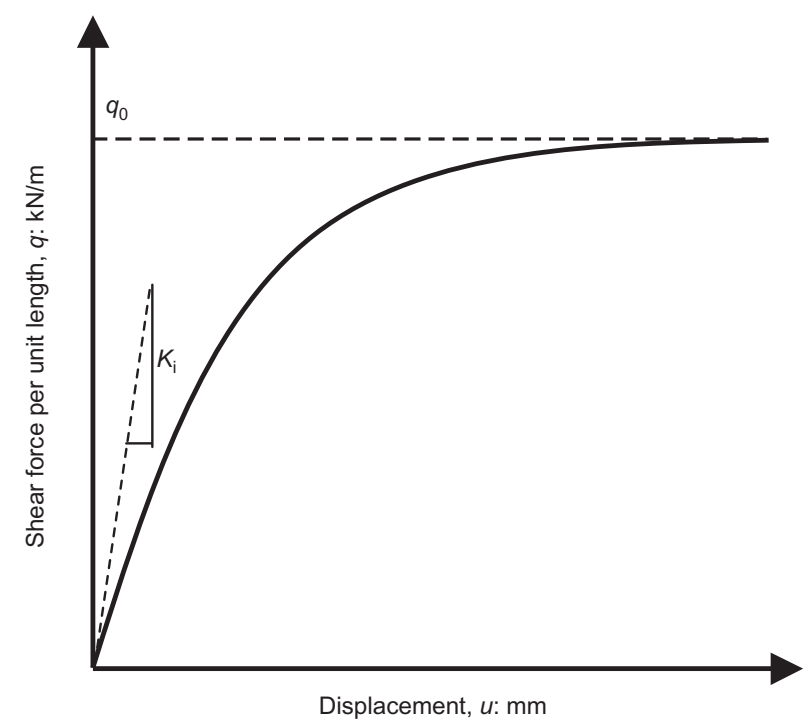

Fig. 1. Shaft/soil interface force-displacement relationship for a non-linear spring-slider system 
LOAD-DISPLACEMENT RELATIONSHIPS FOR

\section{HYPERBOLIC SHAFT/SOIL INTERFACE}

Because of the installation methods used for drilled shafts, the load transfer occurs by way of the shaft/soil interface along the length of the interaction zone, $L_{\mathrm{b}}$, shown in Fig. 2. The remainder of the shaft/soil interface is considered to be non-interacting, having negligible shear resistance. The length of the non-interaction zone, $L_{\mathrm{d}}$, is considered to be the top 0.3 to $1.5 \mathrm{~m}$ depending upon the ground disturbance, fill placement, frost depth and construction process employed.

Based upon the procedure presented by Scott (1981) in the context of pile analysis, the following governing equation may be obtained by considering the equilibrium of slice $\Delta z$, (Misra \& Chen, 2004):

$$
K_{\mathrm{m}} \frac{\mathrm{d}^{2} u}{\mathrm{~d} z^{2}}-K u=0
$$

where $K_{\mathrm{m}}$ is the shaft axial stiffness, $K$ is the load-dependent shear modulus of the shaft/soil interface subgrade reaction and $u$ is the vertical displacement. The appropriate boundary conditions are the applied load $P$ at the shaft head and the tip force $P_{t}$ which may be given in terms of the tip displacement $u_{\mathrm{t}}$ by

$$
P_{\mathrm{t}}=K_{\mathrm{t}} u_{\mathrm{t}}
$$

where $K_{\mathrm{t}}$ is the tip soil stiffness. Based upon theories for a rigid punch bearing upon an elastic half-space, the tip soil stiffness may be related to the shaft diameter and the elastic properties of tip soil according to (Johnson, 1985)

$$
K_{\mathrm{t}}=\frac{0 \cdot 3 \pi D E_{\mathrm{s}}}{1-\mu_{\mathrm{s}}^{2}}
$$

where $E_{\mathrm{s}}$ is the tip soil elastic modulus, $\mu_{\mathrm{s}}$ is the tip soil Poisson's ratio and $D$ is the shaft diameter.

As the compressive load on the drilled shaft increases, the percentage of the load carried by the tip soil also increases. At some load, the shaft/soil interface will yield completely, and the soil at the tip of the drilled shaft will carry all additional load. The ultimate capacity of the tip soil can be determined assuming a punching shear failure, such as the following given by Coduto (2001):

$$
P_{\text {utip }}=q_{\mathrm{t}} A_{\mathrm{m}}
$$

where $q_{\mathrm{t}}$ is the unit toe bearing resistance and $A_{\mathrm{m}}$ is the cross-sectional area of the drilled shaft. Most foundation design textbooks contain formulae for the determination of the unit toe bearing resistance based upon the tip soil properties.

For a non-linear shaft/soil interface modelled by a hyper-

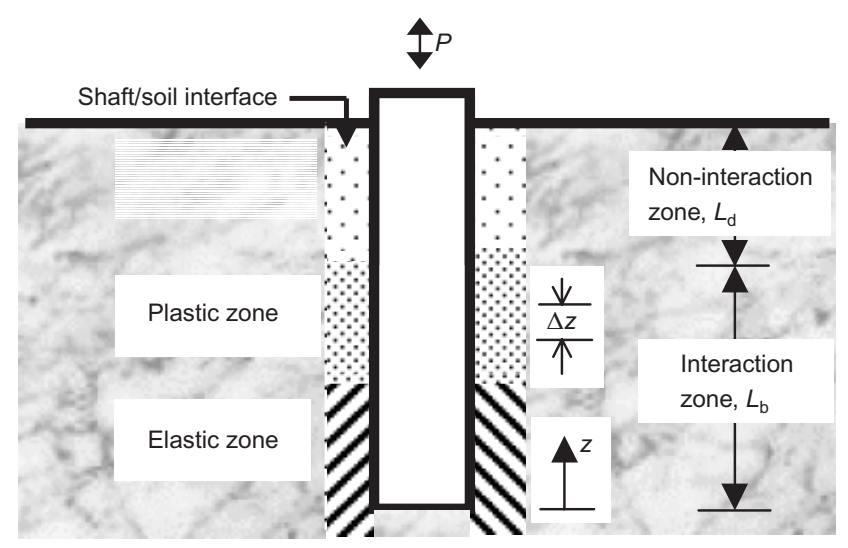

Fig. 2. Schematic of installed drilled shaft bolic relationship, the governing equation (3) cannot be solved in closed form. Therefore, in this paper, the finite difference method to solve equation (3) numerically is utilised. Finite difference techniques for this type of differential equation are widely available, and the specifics of the method will not be repeated here.

\section{MONTE CARLO SIMULATIONS}

The shaft/soil interface parameters $K_{\mathrm{i}}$ and $\tau_{\mathrm{u}}$ are assumed to be random variables, with their variability modelled by the log-normal probability distribution function. The tip stiffness $K_{\mathrm{t}}$ was not considered as a random variable for this study. The present study focuses upon the effect of shaft/soil interface variability on the load-displacement behaviour of drilled shafts installed in deep deposits. For these cases, the tip stiffness predominantly affects the post-yield displacement behaviour of the drilled shaft. Several probabilistic approaches exist for evaluation of functions that involve random variables. Since the load-displacement relationships are non-linear functions of the shaft/soil interface parameters, closed-form probabilistic relations are not possible. Therefore the Monte Carlo simulation method is utilised to obtain the probabilistic load-displacement solutions for the drilled shafts.

During each trial in a Monte Carlo simulation, a random number is generated from within a desired probability distribution function for each shaft/soil interface parameter. The solution is determined using these random numbers, and the process is repeated for a set number of trials. The required number of Monte Carlo trials is based upon achieving a particular confidence level for a specified number of random variables, and is not affected by the variability of the random variables (Fishman, 1995; Harr, 1996; Baecher \& Christian, 2003). Using the procedure described by Harr (1996), the number of Monte Carlo trials required for a confidence level of $90 \%$ is approximately 4500 . For the probabilistic calculations reported in this paper, Monte Carlo simulations with 5000 trials were conducted.

A computer program was written utilising Mathcad (2002) to generate load-displacement relationships based upon the described $t-z$ model and the Monte Carlo simulation method. The shaft/soil interface parameters were assigned mean values that were back-calculated from load-displacement data given in Phoon et al. (1995) for a series of drilled shafts installed at a number of different sites. Using these data, a mean of $90 \mathrm{kPa}$ was determined for $\tau_{\mathrm{u}}$, a mean of $89 \mathrm{MPa}$ was determined for $K_{\mathrm{i}}$, and the COV was determined to be approximately 0.30 for each parameter. However, the COV for each random variable was varied from 0.20 to 0.70 in the simulations. This variation was desired in order to conduct a parametric study of the effect of COV on the magnitude of the resistance factor. In addition, this range was assumed to represent the minimum and maximum magnitude that is likely to occur for the shaft/soil interface, and is consistent with recommendations made by Paikowsky et al. (2004) for characterisation of site variability ranging from 'low' to 'high' and based on engineering judgement or observed subsurface conditions. It should be noted that a COV of 0.30 signifies that a random variable can assume values $90-100 \%$ lower or higher than the mean value (Lacasse \& Nadim, 1996). Thus the range of shaft/soil interface parameter values used in the simulations can be quite large. However, this is not unexpected when one considers all the different sources of variability. The COV was assumed not only to account for inherent variability, but also to incorporate other sources of variability, such as measurement errors and construction techniques. In the simulations, the diameters of the drilled shafts analysed were 
$910 \mathrm{~mm}, 1210 \mathrm{~mm}$ and $1520 \mathrm{~mm}$, with drilled shaft interaction zone lengths of $10 \mathrm{~m}, 20 \mathrm{~m}$ and $30 \mathrm{~m}$. In all the simulations, the additional drilled shaft and tip soil parameters were as follows: $L_{\mathrm{d}}=1 \mathrm{~m}, E_{\mathrm{s}}=100 \mathrm{MPa}, \mu_{\mathrm{s}}=$ $0 \cdot 40, E_{\mathrm{m}}=26300 \mathrm{MPa}$ (drilled shaft elastic modulus) and $q_{\mathrm{t}}=2500 \mathrm{kPa}$.

Figure 3 gives a plot of typical load-displacement curves for the first 20 Monte Carlo simulations for a drilled shaft with $D=910 \mathrm{~mm}$ and $L_{\mathrm{b}}=10 \mathrm{~m}$. These load-displacement curves were generated for a COV of the shaft/soil interface parameters equal to $0 \cdot 30$, and using the shaft and tip soil parameters as given above. Classic hyperbolic curves are obtained, characterised by a shear modulus of subgrade reaction that decreases with increasing load, a pseudo yield point at which the shaft/soil interface yields completely and a point of ultimate failure that occurs when the tip of the drilled shaft fails by plunging.

In addition, the mean values for $\tau_{\mathrm{u}}$ and $K_{\mathrm{i}}$ were varied in order to represent shaft/soil interface profiles that could be described as soft, stiff and hard. Probabilistic analyses were conducted with a mean value for $\tau_{\mathrm{u}}$ and $K_{\mathrm{i}}$ equal to \pm 1 standard deviation from the mean values of $90 \mathrm{kPa}$ and $89 \mathrm{MPa}$ respectively, assuming a COV of $0 \cdot 50$. These mean values were chosen merely for simplicity in the simulations, and these analyses were conducted only for the $910 \mathrm{~mm}$ diameter drilled shaft, primarily because of the simulation processing time required for the larger-diameter drilled shafts. However, drilled shafts with interaction zone lengths of $10 \mathrm{~m}, 20 \mathrm{~m}$ and $30 \mathrm{~m}$ were analysed.

A preliminary study was also performed to assess the effect of vertical fluctuation on the variability of loaddisplacement behaviour. The shaft/soil interface parameters were varied randomly along the interaction zone length of the drilled shaft. The following parameters were used: mean $\tau_{\mathrm{u}}=90 \mathrm{kPa}$, mean $K_{\mathrm{i}}=89 \mathrm{MPa}, \mathrm{COV}$ of $\tau_{\mathrm{u}}$ and $K_{\mathrm{i}}=5 \%$, $D=910 \mathrm{~mm}$ and $L_{\mathrm{b}}=10 \mathrm{~m}$. The drilled shaft was discretised into 100 nodes, and at each node the shaft/soil interface parameters were randomly specified, starting with a new seed for each simulation. The load-displacement curves were analysed to develop frequency diagrams for the drilled shaft load capacity at displacements of $10 \mathrm{~mm}$ and $20 \mathrm{~mm}$. The COV of the load capacities was found to be approximately $1.2 \%$ for both $10 \mathrm{~mm}$ and $20 \mathrm{~mm}$ displacements. The result indicates that the vertical fluctuations tend to average out, resulting in a smaller variability of the axial loaddisplacement behaviour. In a simulation that separately considers the horizontal and vertical fluctuations, the load capacity COV will be more affected by the COV of the horizontal fluctuations. If the fluctuations are lumped together by considering a higher $\mathrm{COV}$ of the horizontal

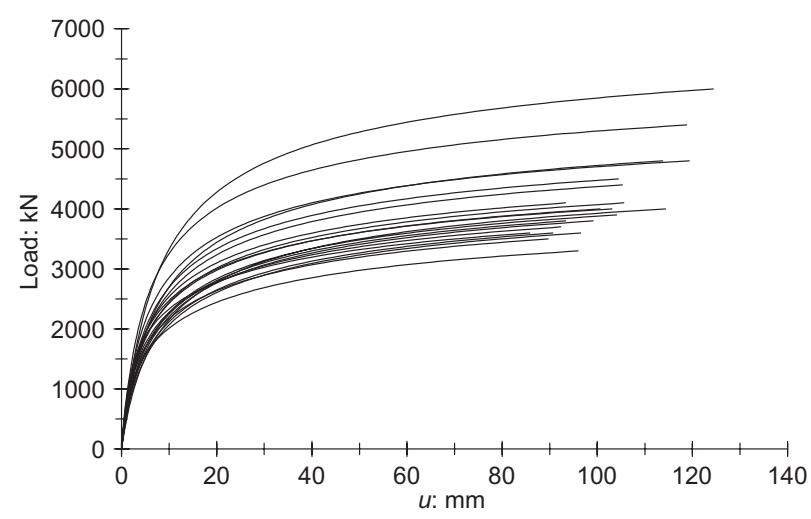

Fig. 3. Load-displacement curves for first 20 Monte Carlo simulation analyses for $910 \mathrm{~mm}$ diameter drilled shaft assuming COV of shaft/soil interface parameters of $0 \cdot 30$ fluctuations, as has been done in this paper, conservative results are obtained.

\section{RELIABILITY INDEX}

Using the load-displacement data obtained from the Monte Carlo simulations, it is possible to calculate load capacity frequency diagrams for the drilled shafts based upon an allowable displacement of $10 \mathrm{~mm}$ and $20 \mathrm{~mm}$ (Misra \& Roberts, 2006). Fig. 4 shows the calculated frequency diagram for the drilled shaft load capacity (resistance) for a $910 \mathrm{~mm}$ diameter drilled shaft based upon an allowable head displacement of $10 \mathrm{~mm}$. Since these data are discrete, the frequency diagram is plotted as discrete points joined by straight lines. For comparison, the best-fit log-normal distribution function is also plotted in Fig. 4, as shown by the dotted line. The allowable displacements of $10 \mathrm{~mm}$ and $20 \mathrm{~mm}$ were chosen based upon typical allowable differential and total settlement allowances used in geotechnical design (Skempton \& MacDonald, 1956; BurBurland \& Wroth, 1974; Barker et al., 1991). If one assumes that the load acting on the drilled shaft is deterministic, the probability of service limit state failure can be determined using Fig. 4 by determining the cumulative frequency corresponding to the value of the deterministic load (Misra \& Roberts, 2005, 2006).

Alternatively, if the load acting on the drilled shaft is assumed to be probabilistic, then the area where the load and load capacity histograms overlap, marked by the shaded area in Fig. 5, represents the combinations in which service limit state failure will occur. The ratio of the shaded area to the total area under both histograms is defined as the probability of service limit state failure, $p_{\mathrm{f}}$, for the system, and represents the level of design risk for the system (FHWA, 1999). The probability of service limit state failure may be used to determine the reliability index $\beta$ from

$$
\beta=-\Phi^{-1}\left(p_{\mathrm{f}}\right)
$$

where $\Phi(\cdot)$ is the cumulative standard normal distribution function.

The reliability index is an alternative method for presenting the probability of service limit state failure on a more convenient scale, since probability of failure is difficult to assess when its value is very small (Kulhawy \& Phoon, 1996). The reliability index also removes the negative connotation associated with the word 'failure', especially for service limit state design. The relationship between the reliability index and the probability of failure is given in

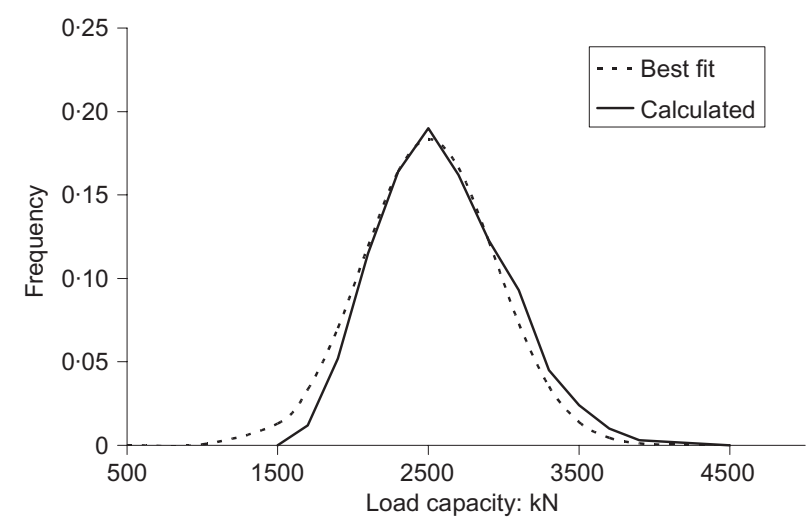

Fig. 4. Frequency diagram for service limit state load capacity for $910 \mathrm{~mm}$ diameter, drilled shaft given an allowable head displacement of $10 \mathrm{~mm}$ and $L_{\mathrm{b}}=10 \mathrm{~m}(\mathrm{Load}$ capacity statistics: $\mu=2598 \mathrm{kN}, \sigma=430 \mathrm{kN}, \mathrm{COV}=0 \cdot 166$ ) 


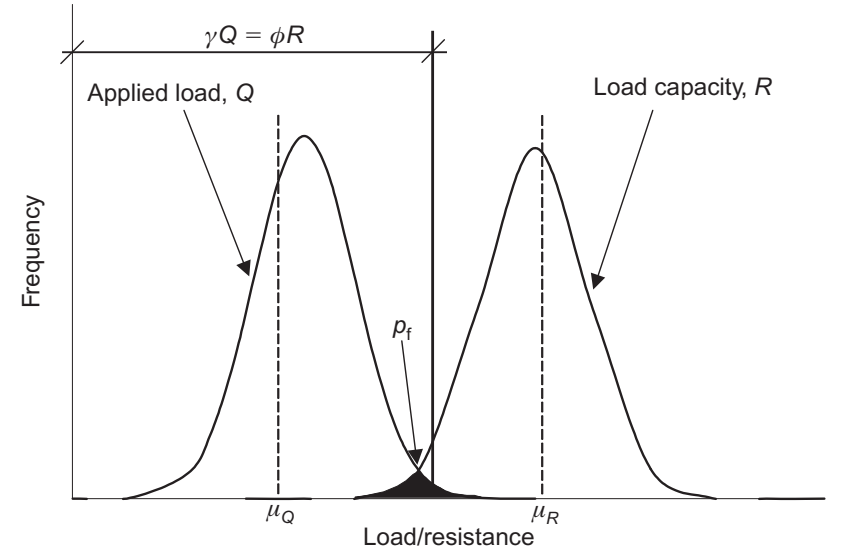

Fig. 5. Normalised probability distributions of load and load capacity (resistance) at service limit state

numerous publications (e.g. Phoon et al., 1995). It is noteworthy that $p_{\mathrm{f}}$ decreases as $\beta$ increases, but the relationship is not linear.

It becomes economically desirable in engineering design to provide the same reliability index from one system to the next. This ensures that the probability of failure for any design is known, and is consistent with the design intentions and operation of the system. However, performing a complicated reliability analysis to determine the probability of failure for every design can be quite cumbersome and time consuming. Therefore, for routine designs with no unusual risks, a simplified approach that includes the use of lumped factors may be utilised (Phoon et al., 1995). Following this approach, resistance factors may be developed for the drilled shaft load capacity at the service limit state based upon the LRFD method, such as that used in the AASHTO LRFD design specifications (AASHTO, 2004).

\section{SERVICEABILITY RESISTANCE FACTORS}

The use of resistance factors in service limit state design has several advantages. First, most engineers are familiar with using resistance factors and can directly assess how the global factor of safety of the design is accounted for by the resistance factor. Second, by using resistance factors, the engineer does not need to perform complicated probability computations. Finally, the resistance factors may be calibrated to produce designs that consistently achieve the desired level of reliability (Phoon et al., 1995).

In addition to the COV of the loads and load capacity (resistance), the bias of the loads and resistance must be determined in order to obtain the resistance factors. Moreover, the target reliability index $\beta_{\mathrm{T}}$ must be defined. Since the reliability index is related to the probability of failure of the system, failure rates estimated from actual case histories can provide guidance in the design of a system at the ultimate limit state (Kulhawy \& Phoon, 1996). A review of the literature showed that a target reliability index equal to 3.2 at the ultimate limit state corresponds well with global factor of safety designs and empirical rates of failure for foundations adjusted to theoretical failure rates (Kulhawy \& Phoon, 1996). Because the consequences of exceeding an allowable displacement are much less than for exceeding an ultimate capacity, one would expect the target reliability index to be less for the service limit state. With this in mind, and based upon research conducted by Phoon et al. (1995), a target reliability index of 2.6 was utilised herein, which corresponds to a probability of failure approximately equal to $0 \cdot 5 \%$.

Assuming that the load capacity histogram follows the log-normal distribution, an assumption commonly made in geotechnical and structural engineering, the resistance factor $\phi$ can be calculated as (Baecher \& Christian, 2003)

$$
\phi=\frac{\lambda_{\mathrm{R}}\left[\frac{\gamma_{\mathrm{D}} E\left(Q_{\mathrm{D}}\right)}{E\left(Q_{\mathrm{L}}\right)}+\gamma_{\mathrm{L}}\right] \sqrt{\frac{1+\Omega_{\mathrm{QD}}^{2}+\Omega_{\mathrm{QL}}^{2}}{1+\Omega_{\mathrm{R}}^{2}}}}{\left[\lambda_{\mathrm{QD}} \frac{E\left(Q_{\mathrm{D}}\right)}{E\left(Q_{\mathrm{L}}\right)}+\lambda_{\mathrm{QL}}\right] \mathrm{e}^{\beta_{\mathrm{T}} \sqrt{\ln \left[\left(1+\Omega_{\mathrm{R}}^{2}\right)\left(1+\Omega_{\mathrm{QD}}^{2}+\Omega_{\mathrm{QL}}^{2}\right)\right]}}}
$$

where $\lambda_{\mathrm{R}}$ is the bias of the resistance; $\lambda_{\mathrm{QD}}$ and $\lambda_{\mathrm{QL}}$ are the biases of the dead load and live load respectively; $\gamma_{\mathrm{D}}$ and $\gamma_{\mathrm{L}}$ are the load factors for the dead load and live load respectively; $\Omega_{\mathrm{QD}}, \Omega_{\mathrm{QL}}$ and $\Omega_{\mathrm{R}}$ are the COV for the dead load, live load and resistance respectively; and $E\left(Q_{\mathrm{D}}\right)$ and $E\left(Q_{\mathrm{L}}\right)$ are the expected values of the dead load and live load respectively. The resistance factor $\phi$ defined above is used in LRFD as a multiplier, and is very different from the partial resistance factor $\gamma_{\mathrm{R}}$ defined in Eurocode 7, which is used as a divider.

In the calculations, the values for the bias of the dead load and live load, assumed as 1.03 and 1.15 respectively, along with the COV of the dead load and live load, assumed as 0.08 and 0.18 respectively, were taken from Baecher \& Christian (2003) and are based upon typical observed values for highway bridges. The load factors were assigned values of unity based upon the AASHTO LRFD Bridge Design Specifications (AASHTO, 2004) for the Service I Limit State, which considers the operation of a structure under the normal dead and live loads. The ratio of the expected dead load to the expected live load does not significantly affect the value of the resistance factor (Baecher \& Christian, 2003; Paikowsky et al., 2004). Therefore this ratio was arbitrarily set as $2 \cdot 0$, based upon an assumed typical value for a highway bridge. The bias of the resistance was assumed to be $1 \cdot 0$, given that test data adopted from Phoon et al. (1995) were utilised to establish mean values of the shaft/soil interface parameters. Since the $t-z$ method has been found to fit most load-displacement data, a bias of unity is a reasonable assumption for most cases.

The COVs of the load capacity at an allowable head displacement of $10 \mathrm{~mm}$ and $20 \mathrm{~mm}$ were obtained using the data generated from the Monte Carlo simulations and substituted into equation (8) to calculate the resistance factor. Figs $6(\mathrm{a}), 6(\mathrm{~b})$ and $6(\mathrm{c})$ provide the service limit state resistance factors for $910 \mathrm{~mm}, 1210 \mathrm{~mm}$ and $1520 \mathrm{~mm}$ diameter drilled shafts respectively. The lengths reported in Fig. 6 refer to the drilled shaft interaction zone length. It is observed that the resistance factors at the two displacements differ by a small amount. This small difference can be attributed to the estimation errors inherent in the Monte Carlo simulations, and to the shape and spread of the load-displacement curves at various interaction zone lengths. It is interesting to note that in all three sets of graphs in Figs 6(a), 6(b) and 6(c) the graph for $20 \mathrm{~mm}$ allowable settlement is above the graph for $10 \mathrm{~mm}$ settlement for the $10 \mathrm{~m}$ interaction distance but below it for the $20 \mathrm{~m}$ and $30 \mathrm{~m}$ interaction distances. Such a result is caused by the non-linear nature of the loaddisplacement relationship and the fact that the shape of the load-displacement curve is a complex function of the interaction length, the shaft diameter, the model parameters and their variability. Any change in these affects the COV of the load capacity at the assumed allowable settlement. In addition, at a different allowable settlement, the COV of the load capacity, and thus the magnitude of the resistance factor, is different. Therefore it appears that resistance factors for use in the design of deep foundations should ideally be computed for each design scenario using site-specific data and variability. The designer can use Figs 6(a)-6(c) as a first 


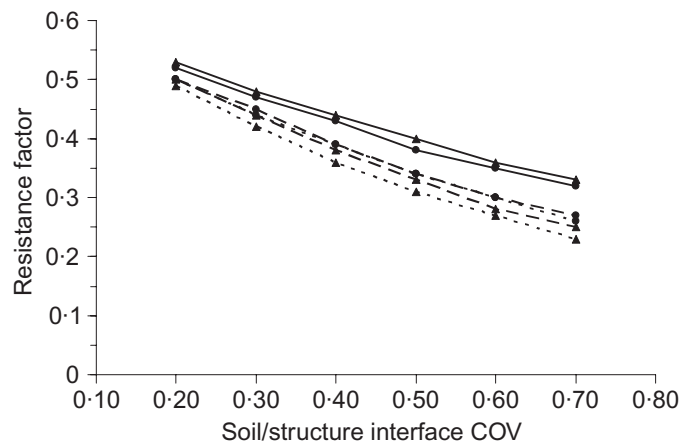

(a)

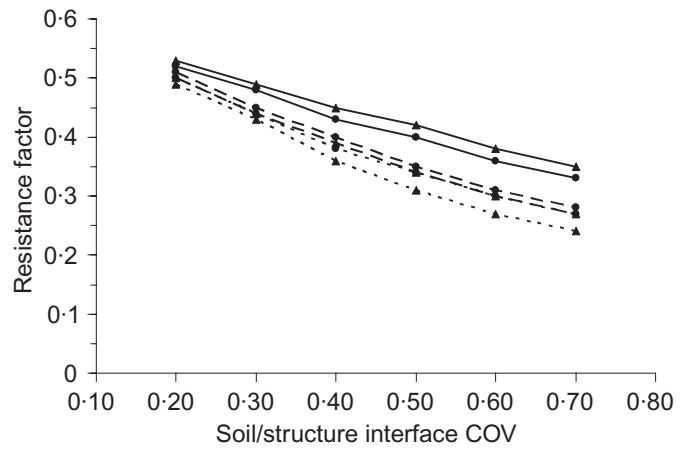

(b)

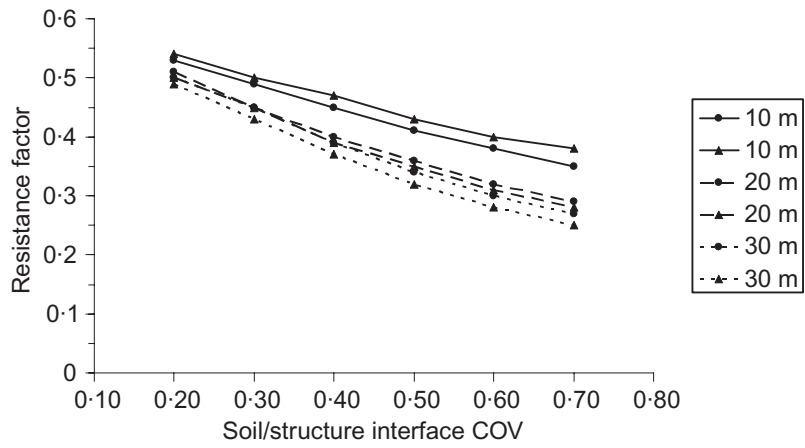

(c)

Fig. 6. Service limit state resistance factor against $\mathrm{COV}$ of shaft/ soil interface parameters for (a) $910 \mathrm{~mm}$, (b) $1210 \mathrm{~mm}$, (c) $1520 \mathrm{~mm}$ diameter drilled shaft of varying interaction zone length (๑, allowable head displacement of $10 \mathrm{~mm} ; \Delta$, allowable head displacement of $20 \mathrm{~mm}$ )

estimate of the value of the resistance factor for use in a design based upon known drilled shaft dimensions and assumed variability of the shaft/soil interface.

The average resistance factors for each drilled shaft diameter and shaft/soil interface parameter COV have been provided in Table 1. The averages are presented in two ways: (a) the average resistance factors obtained by averaging, for each of the drilled shaft diameters, the factors over the drilled shaft interaction zone length for the two allowable head displacements; and (b) the overall average resistance factor. In addition, the recommended values of the resistance factor for service limit state design, rounded to the nearest $0 \cdot 05$, are given.

As stated previously, Monte Carlo simulations were also performed where the mean value of the shaft/soil interface parameters, $K_{\mathrm{i}}$ and $\tau_{\mathrm{u}}$, were varied independently. These calculations were performed for a $910 \mathrm{~mm}$ diameter drilled shaft with shaft interaction zone lengths of $10 \mathrm{~m}, 20 \mathrm{~m}$ and $30 \mathrm{~m}$. The simulations were conducted with the following mean values of the shaft/soil interface parameters: (a) $K_{\mathrm{i}}=$ $45 \mathrm{MPa}$ and (b) $K_{\mathrm{i}}=135 \mathrm{MPa}$ for mean $\tau_{\mathrm{u}}=90 \mathrm{kPa}$; (c)
Table 1. Average and recommended design resistance factors for various drilled shaft diameters at varying shaft/soil interface parameter COV values with $\mu\left(K_{\mathrm{i}}\right)=89 \mathrm{MPa}$ and $\mu\left(\tau_{\mathrm{u}}\right)=90 \mathrm{kPa}$

\begin{tabular}{|c|c|c|c|c|c|}
\hline \multirow{2}{*}{$\begin{array}{l}\text { Shaft- } \\
\text { soil } \\
\text { COV }\end{array}$} & \multicolumn{3}{|c|}{ Average } & \multirow{2}{*}{$\begin{array}{l}\text { Overall } \\
\text { average }\end{array}$} & \multirow[t]{2}{*}{ Design } \\
\hline & $910 \mathrm{~mm}$ & $1210 \mathrm{~mm}$ & $1520 \mathrm{~mm}$ & & \\
\hline $0 \cdot 20$ & $0 \cdot 51$ & $0 \cdot 51$ & $0 \cdot 51$ & $0 \cdot 51$ & $0 \cdot 50$ \\
\hline $0 \cdot 30$ & $0 \cdot 45$ & $0 \cdot 46$ & $0 \cdot 46$ & $0 \cdot 46$ & $0 \cdot 45$ \\
\hline $0 \cdot 40$ & $0 \cdot 40$ & $0 \cdot 40$ & $0 \cdot 41$ & $0 \cdot 40$ & $0 \cdot 40$ \\
\hline $0 \cdot 50$ & $0 \cdot 35$ & $0 \cdot 36$ & $0 \cdot 37$ & $0 \cdot 36$ & $0 \cdot 35$ \\
\hline $0 \cdot 60$ & $0 \cdot 31$ & $0 \cdot 32$ & $0 \cdot 33$ & $0 \cdot 32$ & $0 \cdot 30$ \\
\hline $0 \cdot 70$ & $0 \cdot 28$ & $0 \cdot 29$ & $0 \cdot 30$ & $0 \cdot 29$ & $0 \cdot 30$ \\
\hline
\end{tabular}

$\tau_{\mathrm{u}}=45 \mathrm{kPa}$ and (d) $\tau_{\mathrm{u}}=135 \mathrm{kPa}$ for mean $K_{\mathrm{i}}=89 \mathrm{MPa}$. The magnitudes of these values were chosen with the intention of representing shaft/soil profiles for a variety of typical site conditions. The resistance factors determined from these analyses are summarised in Tables 2 and 3. Comparison of Tables 1, 2 and 3 shows only a slight variation in the overall average resistance factors for a given shaft/soil interface COV. Consequently, it is reasonable to consider the recommended value of the resistance factor for service limit state design rounded to the nearest $0 \cdot 05$. For the shaft/soil interface parameter COV ranging from 0.20 to $0 \cdot 70$, the recommended service limit state resistance factors range from $0 \cdot 50$ to $0 \cdot 30$. Interestingly, the ultimate limit state resistance factors that have been reported in the literature range between $0 \cdot 80-0 \cdot 50$ (AASHTO, 2004) and $0 \cdot 85-0 \cdot 40$ for redundant and $0 \cdot 75-0.30$ for non-redundant structures (Paikowsky et al., 2004). In this paper the service limit state resistance factors have been calculated using load factors of unity. If load factors typically recommended for ultimate limit state

Table 2. Average and recommended design resistance factors for $910 \mathrm{~mm}$ diameter drilled shaft at varying shaft/soil interface parameter COV values and varying $\mu\left(K_{\mathrm{i}}\right)$ with $\mu\left(\tau_{\mathrm{u}}\right)=90 \mathrm{kPa}$

\begin{tabular}{l|c|c|c|c}
\hline \multirow{2}{*}{$\begin{array}{l}\text { Shaft-soil } \\
\text { COV }\end{array}$} & \multicolumn{2}{|c|}{ Average } & \multirow{2}{*}{$\begin{array}{c}\text { Overall } \\
\text { average }\end{array}$} & Design \\
\cline { 2 - 3 } & $\begin{array}{c}\mu\left(K_{\mathrm{i}}\right)=45 \\
\mathrm{MPa}\end{array}$ & $\begin{array}{c}\mu\left(K_{\mathrm{i}}\right)=135 \\
\mathrm{MPa}\end{array}$ & & \\
\hline $0 \cdot 20$ & 0.52 & 0.50 & 0.51 & 0.50 \\
$0 \cdot 30$ & 0.47 & 0.45 & 0.46 & 0.45 \\
$0 \cdot 40$ & 0.43 & 0.39 & 0.41 & 0.40 \\
0.50 & 0.38 & 0.34 & 0.36 & 0.35 \\
$0 \cdot 60$ & 0.35 & 0.30 & 0.32 & 0.30 \\
0.70 & 0.32 & 0.26 & 0.29 & 0.30 \\
\hline
\end{tabular}

Table 3. Average and recommended design resistance factors for $910 \mathrm{~mm}$ diameter drilled shaft at varying shaft/soil interface parameter COV values and varying $\mu\left(\tau_{\mathrm{u}}\right)$ with $\mu\left(K_{\mathrm{i}}\right)=89 \mathrm{MPa}$

\begin{tabular}{l|c|c|c|c}
\hline \multirow{2}{*}{$\begin{array}{l}\text { Shaft-soil } \\
\text { COV }\end{array}$} & \multicolumn{2}{|c|}{ Average } & \multirow{2}{*}{$\begin{array}{c}\text { Overall } \\
\text { average }\end{array}$} & Design \\
\cline { 2 - 3 } & $\begin{array}{c}\mu\left(\tau_{\mathrm{u}}\right)=45 \\
\mathrm{MPa}\end{array}$ & $\begin{array}{c}\mu\left(\tau_{u}\right)=135 \\
\mathrm{MPa}\end{array}$ & & \\
\hline 0.20 & 0.52 & 0.51 & 0.52 & 0.50 \\
0.30 & 0.47 & 0.45 & 0.46 & 0.45 \\
0.40 & 0.43 & 0.40 & 0.41 & 0.40 \\
0.50 & 0.38 & 0.35 & 0.36 & 0.35 \\
0.60 & 0.35 & 0.31 & 0.33 & 0.30 \\
0.70 & 0.31 & 0.28 & 0.29 & 0.30 \\
\hline
\end{tabular}


were to be applied in the calculations presented herein, along with a target reliability index $\beta_{\mathrm{T}}$ of $3 \cdot 2$, the service limit state resistance factors would be comparable to the ultimate limit state resistance factors reported in the literature.

\section{DISCUSSION OF RESULTS \\ Drilled shaft diameter}

For a given shaft/soil interface parameter COV and allowable displacement, the resistance factor increases with the diameter of the drilled shaft, albeit not significantly. Naturally, as the diameter of the drilled shaft was increased, the load-carrying capacity of the drilled shaft also increased. A majority of this increase in load capacity is due to the larger bearing area on the tip soil. Since the tip soil was not assumed to be a random variable in the probabilistic analyses, the variability of the load-displacement behaviour did not increase. Therefore, since the increase in capacity is predominately due to a deterministic model parameter, the resistance factor is expected to increase. However, as observed in Table 1, the increase in the resistance factor was typically of the order of $0.01-0.02$ in going from the $910 \mathrm{~mm}$ diameter shaft to the $1520 \mathrm{~mm}$ diameter shaft, which can be considered negligible, especially since resistance factors are typically rounded to the nearest 0.05 (Baecher \& Christian, 2003).

\section{Drilled shaft interaction zone length}

From the results in Fig. 6, for a given shaft/soil interface parameter $\mathrm{COV}$ and allowable displacement, the resistance factor decreases as the length of the drilled shaft interaction zone increases. Again, an increase in the load-carrying capacity of the drilled shaft was observed as the interaction zone length was increased. However, this increase in capacity is due to the increase in side resistance along the shaft/ soil interface. The strength and stiffness parameters of the shaft/soil interface were defined as random variables during the probabilistic analysis, thereby increasing the variability of the capacity. Fig. 7 displays load-displacement curves for a $910 \mathrm{~mm}$ diameter drilled shaft, calculated for three interaction zone lengths, with a mean value of the shaft/soil interface parameters $K_{\mathrm{i}}=89 \mathrm{MPa}$ and $\tau_{\mathrm{u}}=90 \mathrm{kPa}$ and a $\mathrm{COV}$ of these parameters equal to $0 \cdot 50$. The load-displacement curves are shown for shaft/soil interface parameters equal to the mean \pm 1 standard deviation. It is observed that, as the length of the drilled shaft interaction zone is in-

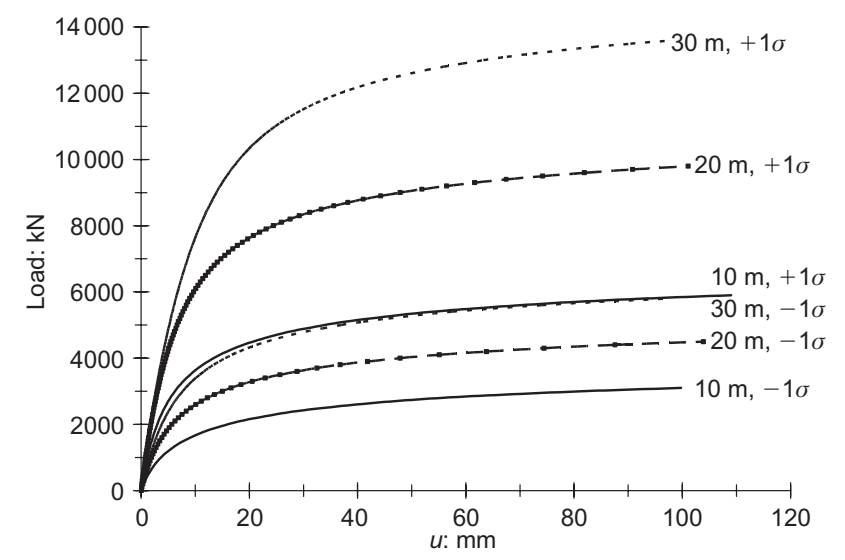

Fig. 7. Load-displacement curves for $910 \mathrm{~mm}$ diameter drilled shaft of various interaction zone lengths $( \pm 1$ standard deviation from mean values of $K_{\mathrm{i}}$ and $\tau_{\mathrm{u}}$ equal to $89 \mathrm{MPa}$ and $90 \mathrm{kPa}$ respectively, with $\mathrm{COV}$ of $\mathbf{0 . 5 0}$ ) creased, the range between the load-displacement curves is also increased. This will result in greater displacement variability, and consequently a decrease in the resistance factor. From Fig. 6(a), the decrease in the resistance factor was observed to be 0.03 at the lowest shaft/soil interface parameter COV value of $0 \cdot 2$, to nearly $0 \cdot 10$ at the highest shaft/soil interface parameter COV value of $0 \cdot 70$.

In the finite difference solution the number of nodes was taken to be 100 for all drilled shaft interaction zone lengths. Therefore the node spacing varied from $100 \mathrm{~mm}$ for the $10 \mathrm{~m}$ drilled shaft to $300 \mathrm{~mm}$ for the $30 \mathrm{~m}$ drilled shaft. This node spacing is considerably smaller than the stability criterion given by Hildebrand (1974),

$$
\Delta z \leqslant 0 \cdot 1 \sqrt{\frac{K_{\mathrm{m}}}{K_{\mathrm{i}}}}
$$

For a $910 \mathrm{~mm}$ diameter drilled shaft with $K_{\mathrm{m}}=17105 \mathrm{MN}$ and $K_{\mathrm{i}}=135 \mathrm{MPa}, \Delta z$ is approximately $1100 \mathrm{~mm}$.

\section{Allowable drilled shaft head displacement}

As observed from Fig. 6, the allowable drilled shaft head displacement had a negligible effect on the resistance factor. This result is expected, as the allowable displacement values chosen for the calculations were typically less than the ultimate displacement of the drilled shaft, but greater than the displacement at which yield of the shaft/soil interface was observed to occur in the simulations. The difference in the resistance factors for a given drilled shaft diameter and length was, typically, in the range 0.01-0.02. However, if one allowable displacement were chosen such that it were less than the displacement at shaft/soil interface yield and another allowable displacement were chosen that were greater than the displacement at shaft/soil interface yield, there could be a significant difference between each resistance factor for the same drilled shaft diameter and length. Therefore the shape of the load-displacement curve can have a significant effect on the magnitude of the resistance factor. This is an important aspect to recognise, as a large number of shaft/soil interface parameters and drilled shaft diameters and lengths are possible in the field.

\section{Shaft/soil interface COV}

Each combination of drilled shaft diameter, length and shaft/soil interface parameters was analysed at six different $\mathrm{COV}$ values for the shaft/soil interface parameters, ranging from $0 \cdot 20$ to $0 \cdot 70$. This range is believed to encompass the minimum and maximum variability in the shaft/soil interface parameters, as observed in the literature. As discussed previously, the higher COV values could also be utilised to account for other uncertainties in the analysis, such as model uncertainties and construction variances. From the results presented above, the resistance factor decreases as the COV of the shaft/soil interface parameters increases for similar drilled shaft diameters and interaction zone lengths. In fact, the difference between the largest resistance factor and smallest resistance factor for similar drilled shaft diameter, interaction zone length and allowable displacements is typically in the range $0 \cdot 20-0 \cdot 25$, which is fairly significant. When the COV of the shaft/soil interface parameters is greater, the variability in the design is greater. As the variability increases, the resistance factor should decrease. In a traditional approach, the designer would utilise a higher factor of safety when the magnitude of the variability is high. This result demonstrates that a single resistance factor cannot account for every possible service limit state design situation in geotechnical engineering. Instead, the design 
engineer must utilise a resistance factor that is consistent with the observed magnitude of variability of the shaft/soil interface parameters due to the horizontal and vertical scale of fluctuation, model uncertainties, measurement errors and construction processes.

\section{Nominal shaft/soil interface parameters}

The mean of each shaft/soil interface parameter, $K_{\mathrm{i}}$ and $\tau_{\mathrm{u}}$, was varied in a series of simulations in order to investigate the effect of the nominal values on the magnitude of the resistance factor as shown in Tables 2 and 3. The shaft/soil interface parameters directly affect the strength and displacement characteristics of the drilled shaft. Consequently, the overall average values of the resistance factor from Tables 2 and 3 differ from the overall average values of the resistance factor reported for the $910 \mathrm{~mm}$ diameter drilled shaft in Table 1. However, as observed from the results in Tables 1, 2 and 3, this difference is small, such that the values of the resistance factors that are recommended for use in design are identical. Although the shapes of the load-displacement curves are different for different mean shaft/soil interface parameters, the COV values of the load capacity frequency diagrams at the assumed displacement are observed to be the nearly identical.

\section{USE OF RESISTANCE FACTORS IN DESIGN}

The use of the resistance factors presented in this paper for design is quite simple. The designer must first develop a load-displacement curve using the $t-z$ method and nominal values for the shaft/soil interface parameters, or utilise a load-displacement curve from an actual field test. Based upon this load-displacement curve, the designer would then determine the load that corresponds to an allowable head displacement. This load is called the nominal load capacity, using standard AASHTO LRFD nomenclature. Finally, the designer would multiply the nominal load capacity by the value of the resistance factor, determined using Fig. 6 and based upon drilled shaft dimensions and assumed site variability, to calculate the factored resistance of the drilled shaft. As long as the factored resistance of the drilled shaft is greater than or equal to the applied factored loads, the drilled shaft design is adequate at the service limit state.

\section{CONCLUSIONS}

This paper presents a probabilistic approach to determine resistance factors for the service limit state design of drilled shafts under compression load. The drilled shaft/soil interface model is considered along the lines of the $t-z$ method, assuming the shaft/soil parameters are constant with depth, but subject to various magnitudes of uncertainty from numerous sources. The shaft/soil interface load-displacement behaviour is assumed to be hyperbolic. Consequently, solutions to this model must be derived using a finite difference technique. To that end, a probabilistic analysis was conducted using the Monte Carlo simulation method. Load capacity frequency distributions were developed based upon an allowable shaft head displacement of $10 \mathrm{~mm}$ and $20 \mathrm{~mm}$. Finally, the statistics of the load capacity histograms were utilised to develop resistance factors for service limit state design.

Numerous probabilistic simulations were conducted by varying the drilled shaft geometry and the shaft/soil interface parameters. In order to present the resistance factor results efficiently, a series of graphs were created that provide the resistance factor against the $\mathrm{COV}$ of the shaft/soil interface parameters using drilled shaft diameter, interaction zone length and allowable head displacement. It was observed that the magnitude of the resistance factor was only slightly affected by drilled shaft geometry (diameter and interaction zone length), allowable shaft head displacement and magnitude of the shaft/soil interface parameters, but was greatly influenced by the variability of the shaft/soil interface parameters (COV). Calibration of the resistance factors by utilising actual load test data to refine the $t-z$ model loaddisplacement curves and adjusting the bias of the resistance would be beneficial; however, the recommended resistance factors appear to be reasonable for design at the service limit state.

\section{NOTATION}

$A_{\mathrm{m}}$ cross-sectional area of drilled shaft

$D$ drilled shaft diameter

$E_{\mathrm{m}} \quad$ drilled shaft elastic modulus

$E_{\mathrm{s}} \quad$ tip soil elastic modulus

$E\left(Q_{\mathrm{D}}\right)$ expected value of dead load

$E\left(Q_{\mathrm{L}}\right)$ expected value of live load

$K$ shear modulus of shaft/soil interface subgrade reaction

$K_{\mathrm{i}}$ initial tangent shear modulus of shaft/soil interface subgrade reaction

$K_{\mathrm{m}} \quad$ drilled shaft axial stiffness

$K_{\mathrm{t}} \quad$ drilled shaft tip soil stiffness

$L_{\mathrm{b}} \quad$ shaft interaction zone length

$L_{\mathrm{d}} \quad$ shaft non-interaction zone length

$P$ applied load

$P_{\mathrm{t}} \quad$ drilled shaft tip force

$P_{\text {utip }} \quad$ ultimate capacity of tip soil

$p_{\mathrm{f}}$ probability of drilled shaft failure

$Q$ dead and live loads

$q$ shear force per unit length

$q_{\mathrm{f}}$ ultimate failure strength of shaft/soil interface

$q_{0}$ ultimate (asymptotic) strength of shaft/soil interface

$q_{\mathrm{t}}$ unit toe bearing resistance

$R$ foundation resistance

$R_{\mathrm{f}}$ failure ratio

$u$ vertical displacement

$u_{\mathrm{t}}$ tip displacement

$\Delta z$ incremental length along drilled shaft

$\beta$ reliability index

$\beta_{\mathrm{T}}$ target reliability index

$\gamma_{\mathrm{D}}$ dead load factor

$\gamma_{\mathrm{L}}$ live load factor

$\lambda_{\mathrm{QD}}$ bias of dead load

$\lambda_{\mathrm{QL}}$ bias of live load

$\lambda_{\mathrm{R}}$ bias of resistance

$\mu()$ mean value of random variable

$\mu_{\mathrm{s}}$ tip soil Poisson's ratio

$\sigma()$ standard deviation of random variable

$\tau_{\mathrm{u}} \quad$ ultimate shear strength of shaft/soil interface

$\phi$ resistance factor

$\Omega_{\mathrm{QD}}$ coefficient of variation of dead load

$\Omega_{\mathrm{QL}} \quad$ coefficient of variation of live load

$\Omega_{\mathrm{R}}$ coefficient of variation of resistance

\section{REFERENCES}

AASHTO (2004). LRFD bridge design specifications, 3rd edn. Washington, DC: American Association of State Highway and Transportation Officials.

Baecher, G. B. \& Christian, J. T. (2003). Reliability and statistics in geotechnical engineering. Chichester: Wiley.

Barker, R. M., Duncan, J. M., Rojiani, K. B., Ooi, P. S. K., Tan, C. K. \& Kim, S. G. (1991). NCHRP Report 343: Manual for the design of bridge foundations. Washington, DC: Transportation Research Board, National Research Council.

Burland, J. B. \& Wroth, C. P. (1974). Settlement of buildings and associated damage. Proceedings of the conference on settlement of structures, Cambridge, pp. 611-654.

Castelli, F. \& Maugeri, M. (2002). Simplified nonlinear analysis for 
settlement prediction of pile groups. J. Geotech. Geoenviron. Engng ASCE 128, No. 1, 76-84.

CEN (2004). Eurocode 7: Geotechnical design-Part 1: General rules, EN 1997-1:2004. Brussels: European Committee on Standardisation.

Coduto, D. P. (2001). Foundation design: Principles and practices. Upper Saddle River, NJ: Prentice Hall.

DFI (1990). Guidelines for the interpretation and analysis of the static loading test, 1st edn. Sparta, NJ: Deep Foundations Institute.

Duncan, J. M. \& Chang, C.-Y. (1970). Nonlinear analysis of stress and strain in soils. J. Soil Mech. Found. Div. ASCE 96, No. SM5, 1629-1653.

Duncan, J. M., Byrne, P., Wong, K. S. \& Marby, P. (1980). Strength, stress-strain, and bulk modulus parameters for finite element analyses of stresses and movements in soil masses, Report No. UCB/GT/80-01. Berkeley, CA: College of Engineering Office of Research Services, University of California-Berkeley.

FHWA (1999). Drilled shafts: Construction procedures and design methods, Report No. FHWA-IF-99-025. McLean, VA: Federal Highway Administration, US Department of Transportation.

Fenton, G. A. \& Griffiths, D. V. (2007). Reliability based deep foundation design. Proc. GeoDenver 2007, Arlington, VA, CD-rom.

Fishman, G. S. (1995). Monte Carlo: Concepts, algorithms, applications. New York: Springer-Verlag.

Harr, M. E. (1996). Reliability-based design in civil engineering. Mineola, NY: Dover Publications.

Hildebrand, F. B. (1974) Introduction to numerical analysis. Mineola, NY: Dover Publications.

Johnson, K. L. (1985). Contact mechanics. London: Cambridge University Press.

Kondner, R. L. (1963). Hyperbolic stress-strain response: cohesive soils. J. Soil Mech. Found. Div. ASCE 89, No. SM1, 115-143.

Kraft, L. M., Ray, R. M. \& Kagawa, T. (1981). Theoretical $t-z$ curves. J. Geotech. Engng Div. ASCE 107, No. 11, 1543-1561.

Kulhawy, F. H. \& Phoon, K. K. (1996). Engineering judgment in the evolution from deterministic to reliability-based foundation design. In Uncertainty '96, Geotechnical Special Publication No. 58, Vol. 1, pp. 29-48. New York: ASCE.
Lacasse, S. \& Nadim, F. (1996). Uncertainties in characterizing soil properties. In Uncertainty '96, Geotechnical Special Publication No. 58, Vol. 1, pp. 49-75. New York: ASCE.

Mathcad (2002). Mathcad version 11. Cambridge, MA: Mathsoft Engineering \& Education, Inc.

Misra, A. \& Chen, C.-H. (2004). Analytical solutions for micropile design under tension and compression. J. Geotech. Geol. Engng 22, No. 2, 199-225.

Misra, A. \& Roberts, L. A. (2005). Probabilistic axial loaddisplacement relationships for drilled shafts. Proc. Geofrontiers 2005, Austin, TX, CD-rom.

Misra, A. \& Roberts, L. A. (2006) Probabilistic analysis of drilled shaft service limit state using ' $t-z$ ' method,' Can. Geotech. J. 43, No. 12, 1324-1332.

Paikowsky, S. G., Birgisson, B., McVay, M., Nguyen, T., Kuo, C., Baecher, G., Ayyub, B., Stenersen, K., O'Malley, K., Chernauskas, L. \& O'Neill, M. (2004). NCHRP Report 507: Load and resistance factor design (LRFD) for deep foundations. Washington, DC: Transportation Research Board, National Research Council.

Phoon, K.-K., Kulhawy, F. H. \& Grigoriu, M. D. (1995) Reliabilitybased design of foundations for transmission line structures, Report TR-105000. Palo Alto, CA: Electric Power Research Institute.

Phoon, K. K. \& Kulhawy, F. H. (1999). Characterization of geotechnical variability. Can. Geotech. J. 36, No. 4, 612-624.

Randolph, M. F. \& Wroth, C. P. (1978). Analysis of deformation of vertically loaded piles. J. Geotech. Engng Div. ASCE 104, No. $12,1465-1488$.

Reese, L. C. \& O’Neill, M. W. (1987). Drilled shafts: Construction procedures and design methods, Report No. FHWA-HI-88-042. McLean, VA: Federal Highway Administration, US Department of Transportation.

Scott, R. F. (1981). Foundation analysis. Englewood Cliffs, NJ: Prentice Hall.

Skempton, A. W. \& MacDonald, D. H. (1956). Allowable settlement of buildings. Proc. Instn Civ. Engrs 5, No. 3, 727-768.

Zhang, L. M. \& Ng, A. M. Y. (2005). Probabilistic limiting tolerable displacements for serviceability limit state design of foundations. Géotechnique 55, No. 2, 151-161. 